\title{
La deconstrucción de Dulcinea. Bases medievales de los modelos femeninos en el Quijote
}

\author{
María Jesús Fuente \\ Universidad Carlos III de Madrid
}

\begin{abstract}
RESUMEN
Dulcinea y las otras mujeres que aparecen en el Quijote configuran un panorama de retratos que dan sentido a la obra, casi tanto como las figuras de don

Quijote y Sancho Panza. Podría compararse la importancia de las mujeres en el Quijote a la que tienen Jimena y sus hijas como soporte de la figura masculina del Campeador en el Poema de Mio Cid.

La remembranza de estas dos obras apunta lo apropiado de buscar en las mujeres medievales los modelos femeninos de Don Quijote. Se ha apuntado que las mujeres del Quijote responden a modelos del Renacimiento o

del Barroco, sin embargo, parecen mantener los valores femeninos de la

Edad Media. Mediante el análisis de retratos, valores y papeles femeninos, se trata de vis/umbrar si continúan los modelos diseñados en la Edad Media o si el Concilio de Trento y el Renacimiento introdujeron cambios importantes en la vida de las mujeres.
\end{abstract}

PALABRAS CLAVE

Mujeres medievales, Don Quijote, Dulcinea.

\begin{abstract}
Women are an important part of Don Quixote, if not as important as Don Quixote and Sancho Panza. Just as the Poema del Mio Cid does not make sense without Jimena and her daughters, so Don Quixote does not make sense without Dulcinea and others like her. In Don Quixote the knight's duties include honoring his lady and fighting for women at risk. Although some scholars have argued that the women of Don Quixote are models of the Renaissance or Baroque, 1 see them more as medieval types.

Through an examination of the women of Don Quixote, their roles and values, their virtues and vices, I show how they reflect much about the Middle Ages, without forgetting the changes brought about by the Council of Trent and the humanism of the Renaissance.
\end{abstract}

KEYWORDS

Medieval women, Don Quixote, Dulcinea. 
Su nombre es Dulcinea... su hermosura sobrehumana, pues en ella se vienen a hacer verdaderos todos tos imposibles y quiméricos atributos de belleza que los poetas dan a las damas: que sus cabellos son oro, su frente campos eliseos, sus cejas arcos de cielo, sus ojos soles, sus mejillas rosas, sus labios corales, perlas sus dientes alabastro su cuello, mármol su pecho, marfil sus manos, su blancura nieve.

Don Quijote, I, $13^{1}$.

El retrato físico de Dulcinea, con esa descripción descendente desde los cabellos a las manos, pasando por la frente, las cejas, los ojos, las mejillas, los labios, los dientes, el cuello y el pecho, responde claramente a los cánones del retrato retórico medieval ${ }^{2}$. Cervantes seguía unos modelos desarrollados en la literatura de los siglos precedentes, y que tenía buenos ejemplos en Melibea, en doña Endrina ${ }^{3}$, o en Santa María Egipciaca. Aunque no parece probable que Cervantes se inspirara en los manuales retóricos a su alcance ${ }^{4}$, es posible que siguiera los modelos medievales «deliberadamente» 5 .

De la misma manera que el retrato físico responde a unos cánones medievales, no sería arriesgado suponer que el retrato moral de Dulcinea siguiera también cánones propios de la Edad Media, y asi tanto las cualidades físicas como las morales de esta mujer idealizada, seguirían fórmulas construidas en los siglos precedentes. Pero el retrato moral, a diferencia del retrato físico, no suele aparecer en un solo párrafo, sino que las cualidades de las mujeres retratadas en las obras li-

' I, 13, parte primera, capitulo 13. Las citas del Quijote se harán poniendo en caracteres romanos la parte de la obra, y en caracteres arábigos el capitulo al que corresponde.

F. LECOY, Recherches sur le Libro de Buen Anor de Juan Ruiz Archiprêtre de Hita, Westmead, 1974 , p. 310 , nota 2. Indica Lecoy que fue M. Faral quien apuntó que las descripciones de personajes femeninos responden a un canon que habia circulado en las escuelas de retórica. Mantiene esta misma teoria E. VERES D'OCON, "Los retratos de Dulcinea y Maritornes", Anales cervantinos, I, 1951, p. 252. Estos retratos retóricos tenian un precedente clásico en la elegía romana (Ovidio. Amores, I, 5).

${ }^{3}$ Quizás el retrato de doña Endrina no es tan expresivo del retrato retórico medieval como lo es el de la dueña del Libro de Buen Amor (estrofas 432-35)

\footnotetext{
Busca muger de talla, de cabeça pequeña, cabellos amarillos, non sean de alheña, las çejas apartadas, luengas, altas en peña. ancheta de caderas: ésta es talla de dueña. Ojos grandes, fermosos, pintados, relusçientes, et de luengas pestañas bien claras e reyentes, las orejas pequeñas, delgadas, para ál mienies, si ha el cuello alto, atal quieren las gentes. La narís afilada, los dientes menudillos, egoales, e bien blancos, un poco apretadillos, las ensivas bermejas, los dientes agudillos, los labros de la boca vermejos, angostillos. La su boca pequeña asi de buena guisa, la su fas sea blanca, sin pelos, clara, e lisa,
}

${ }^{4}$ Los tratados escritos en torno a los siglos xll y xill fueron varios, pero con certeza se sabe que el titulado Poetria nova de Geoffroi de Vinsaut era conocido en España. Sirvio de inspiración al Breve compendium artis rhetorice, de finales del siglo Xill, de Martinus Cordubensis.

${ }^{5}$ E. VERES D OCON, "LOS retratos de Dulcinea y Maritornes", p. 252. 
terarias suelen mostrarse a lo largo de toda la obra ${ }^{6}$; conocer el retrato moral de Dulcinea exige, pues, una lectura minuciosa del Quijote.

Dulcinea es la dama de un caballero andante, una dama medieval dibujada en el siglo XVHi; se la ha identificado, junto a las otras mujeres del Quijote, como ejemplo de las mujeres del Renacimiento o del Barroco ${ }^{7}$; sin embargo, a esa controversia habria que añadir la cuestión de hasta qué punto las cualidades de las mujeres de comienzos del siglo xvı no eran similares a las de sus congéneres de los siglos precedentes, tiempos de construcción de modelos, ideas y valores, que se han extendido durante siglos y han llegado, en algunos aspectos, incluso al siglo $x x$.

Aunque el Quijote sea una fuente excelente para conocer la sociedad de comienzos del siglo XVII, no se ha de olvidar que el análisis en profundidad de una sociedad muestra las capas de sedimentos depositados en tiempos anteriores y que, por tanto, la sociedad retratada en el Quijote es el resultado de los estratos acumulados durante la Edad Media, visibles en algunos casos e invisibles en otros. En los personajes femeninos del Quijote se encuentran «figuras, ideas y problemas " de Juan Ruiz y de Fernando de Rojas ${ }^{8}$, y junto a la influencia de estos autores medievales hay que colocar las doctrinas neoplatónicas, difundidas por Europa en el siglo XV, «sostén del edificio ideológico del Renacimiento»?

En este artículo nos proponemos examinar los modelos femeninos en esta obra de Cervantes, con el objetivo de identificar las influencias medievales en las mujeres de comienzos de siglo XVII, y su posible transformación en la sociedad renacentista, lo que permitirá clasificar a las mujeres del tiempo del Quijote como mujeres renacentistas, barrocas, o simplemente como mujeres de la Edad Media.

En la búsqueda de esas raíces medievales partimos del retrato de Dulcinea, mujer idealizada y representativa del modelo de mujer de un caballero "andante». Como este caballero es, en última instancia, un caballero medieval, las cualidades de su dama responderían a las cualidades de una dama de la Edad Media. Sin embargo, limitarse al personaje de Dulcinea difícilmente permitiría conseguir el ambicioso objetivo de este articulo, que persigue identificar los posibles elementos medievales en la construcción de los modelos de mujer que habían llegado al Siglo de Oro; por ello se han de contemplar las figuras femeninas en su conjunto para conseguir un retrato lo más completo posible de ideas, modelos, valores y otros as pectos del mundo de las mujeres.

S. TRELles, "Rhetorical Canons and Female Portrai's in Pastoral Romances", Spanish Women in the Golden Age, M. S. Sánchez and A. Saint-Saens (eds.), Westport, 1996, p. 158.

7 R. S. LAMB, «Las mujeres del Quijote: contraste entre la mujer renacentista y la mujer barroca», $M$ Criado del VAL, Cervantes, su obra y su mundo. Actas del I Congreso Internacional sobre Cenvantes, Madrid. 1981.

"M. Criado del Val, «Melibea y Celestina ante el juicio de Don Quijote». Anales cenantinos, 4, 1954 p. 187.

${ }^{9}$ A. Castro. El pensamiento de Cenvantes, Barcelona, Noguer, 1980, p. 148. 
Se parte de la idea de que la tradición oral, el mantenimiento de las costumbres y el romancero contribuyeron a la difusión de las ideas construidas en la Edad Media ${ }^{10}$. Cervantes, buen conocedor del romancero, del roman artúrico y de la literatura que habia llegado a su tiempo ${ }^{11}$, pone en palabras de don Quijote la idea de haberle llegado la fama de alguna de las damas medievales también por tradición oral: «me acuerdo yo que me decía una mi agüela, de partes de mi padre, cuando veía alguna dueña con tocas reverendas: "Aquella, nieto, se parece a la dueña Quintañona» De donde arguyo yo que la debió de conocer ella, o, por lo menos, debió de alcanzar a ver algún retrato suyo" $(1,49)$.

Tres van a ser los puntos esenciales que se van a analizar: cómo son las mujeres o cómo las ve la sociedad de su tiempo, qué valores se destacan de ellas, y qué papel se les adjudica en esa sociedad. Para abordar su estudio se analizarán en primer lugar las cualidades de las mujeres en los retratos físicos y morales, en segundo los papeles de las mujeres en la sociedad y en la familia, en el amor y en el matrimonio, como exigencia impuesta por el "orden natural», y por último, la continuación de la querella de las mujeres en los rasgos misóginos o "feministas" que aparecen en el Quijote.

\section{RETRATOS DE MUJER: MODELOS DE HERMOSURA Y DE MESURA}

"su patria, el Toboso, un lugar de la Mancha; su calidad, por lo menos ha de ser de princesa, pues es reina y señora mía".

Don Quijote, I, 13.

Esta caracterización personal, a modo de señas de identidad, completan el retrato de Dulcinea arriba expuesto. La representación de Dulcinea se componía de una parte física, que detallaba minuciosamente sus rasgos desde el pelo hasta el pecho, y otra parte moral, de caracteres personales o de valores humanos que no se muestra en la descripción inicial que de ella hace don Quijote, y cuyo rastro hay que buscar en toda la obra.

El retrato físico de Dulcinea, como el de otras mujeres del Quijote, reúne características singulares que merece la pena resaltar. Como se ha apuntado antes, seguían el método del retrato retórico medieval; lo sigue don Quijote al dibujar a

10 A. MoRel-FATIO, "La prudence chez la femme, drame historique de Tirso de Molina", Etudes sur I'Espagne, París, 1904 : "grâce aux chroniques en langue vulgaire, intelligibles à tous, et grâce aussi aux romanceros dont plusieurs ne sont en quelque sorte que des précis d'histoire pour le peuple, l'idiome, par suite les usages et en une certaine mesure les idées et les sentiments du moyen âge castillain restaient très accesibles à l'Espagne centralisée du xvile siècle..."

1" Acerca del conocimiento de Cervantes de estos géneros literarios: C. RUBIO PACHECO, «EI roman artúrico en la España medieval: problemas para su estudio", Anales Cervantinos, 31, 1993; F. MARQuEZ ViLLANueVA, Personajes y temas del Quijote, Madrid, 1975; S. Zimic, "Sobre los amores de Leandra y Vicente de la Roca (Don Quijote, I caps. 50-52)", Anales Cervantinos, 30, 1992. 
Dulcinea, y en parte lo sigue la doncella Altisidora, cuando se describe a sí misma de forma burlesca:

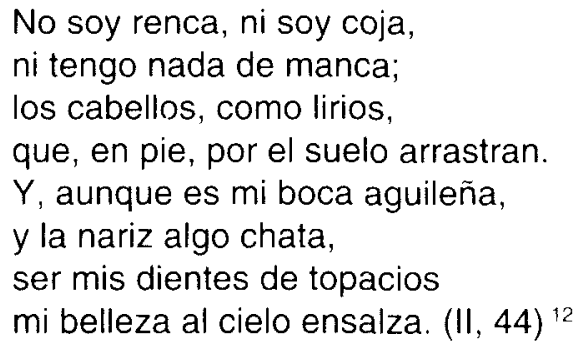

No con tanto detalle, pero de manera minuciosa se describen algunas de las mujeres que aparecen en las distintas historias intercaladas en el Quijote: Marcela, Luscinda, Dorotea, Zoraida, Camila, Antonomasia. Todas tienen una cosa en común, son las mujeres más bellas, aunque para don Quijote no había en el mundo «doncella más hermosa que la emperatriz de la Mancha, la sin par Dulcinea del Toboso» $(1,4)$. Compara a la manchega con una famosa protagonista de un romance anónimo, el del abencerraje y la hermosa Jarifa, inspirado en una historia de comienzos del siglo xv: «esta hermosa Jarifa, que he dicho, es ahora la linda Dulcinea del Toboso, por quien yo he hecho, hago y haré los más famosos hechos de caballerías que se han visto, vean ni verán en el mundo» $(1,5)$. Don Quijote no tolera que alguien pueda poner en entredicho la belleza sin par de su dama, y se enoja con Sancho cuando éste, ante la belleza de Zoraida, se pregunta “¿Es por dicha más hermosa mi señora Dulcinea? No, por cierto; ni aun con la mitad, y aún estoy por decir que no llega a su zapato de la que está delante.» (1, 30).

Sancho pensaría no en la mujer idealizada por su señor, sino en la labradora Aldonza Lorenzo, que como otras labradoras $u$ otras mujeres de nivel social bajo no salían tan bien en los retratos. No eran tan guapas, al contrario, solían ser rollizas, malolientes y bigotudas, curiosamente viriles $u$ "hombrunas» ${ }^{13}$. Esas mujeres eran la antítesis de las damas, como Maritornes, antítesis de Dulcinea, que era una moza asturiana «ancha de cara, llana de cogote, de nariz roma, del un ojo

12 La utilización del método retórico medieval de forma sarcástica ha llevado a algunos autores a plantear que estos retratos de Cervantes siven para "mostrar la pervivencia de las formas retóricas medievales y su transformación y aplicación a los diferentes estilos del Quijote", E. VERES D'OCON, "LOS retratos de Dulcinea y Maritornes", p. 270.

13 La Torralba upastora, que era una moza rolliza, zahareña, y tiraba algo a hombruna, porque tenia unos pocos de bigotes" ( $I, 20$ ). Al encontrarse don Quijote y Sancho con las tres labradoras, e insistir Sancho en que una de ellas era Dulcinea del Toboso, don Quijote considera que sus enemigos "la transformaron y volvieron en una figura tan baja y tan fea como la de aquella aldeana, y juntamente le quitaron lo que es tan suyo de las principales señoras, que es el buen olor por andar siempre entre ámbares y entre flores; porque te hago saber, Sancho, que, cuando llegué a subir a Dulcinea sobre su hacanea, según tú dices, que a mí me pareció borrica, me dio un olor de ajos crudos, que me encalabrinó y atosigó el aima" $(1,10)$. 
tuerta y del otro no muy sana" $(l, 16)$. Maritornes tiene también su modelo en una mujer medieval, la serrana del Libro de Buen Amor que tenia la cabeza muy grande, el pescuezo negro, ancho y velloso, las narices largas, muy gordas, de zarapico y los ojos "fondos, bermejos, poco e mal devisa» ${ }^{14}$.

Las damas tenian cualidades de las que no gozaban las mujeres de baja condición social. Sin embargo, las mujeres del entorno de Sancho, de ese mundo "ordinario" al que él pertenecía, como su mujer Teresa Panza, o su hija Sanchica, no están descritas ni como bellas ni como feas. Probablemente Cervantes quiso respetar al bueno de Sancho. Sin embargo, en los retratos femeninos del Quijote, la belleza física en buena medida parece estar en relación con el nivel social de la mujer pintada. Algunos de los retratos utilizan las comparaciones con objetos preciosos para resaltar los méritos de la mujer ${ }^{15}$, como también se encuentra en la poesía medieval, especialmente en la árabe ${ }^{16}$.

Tras el retrato físico, como se ha apuntado antes, hay que ocuparse del retrato moral, y buscar sus pautas. Los elementos del retrato seguian en buena medida la línea del De inventione de Cicerón ${ }^{17}$, que proponia como atributos personales el nombre, la manera de vida, la fortuna, el hábito, los sentimientos, los intereses, las intenciones, los logros, los accidentes y las palabras pronunciadas. En el propio Quijote se apuntan los elementos que deberian considerarse para hacer el retrato: «... si es de esencia que todo caballero andante haya de ser enamorado - dijo el caminante- le suplico, en nombre de toda esta compañía y en el mío, nos diga el nombre, patria, calidad y hermosura de su dama.". No solo Dulcinea, sino las otras mujeres que aparecen en el Quijote son descritas siguiendo esos modelos, el de la pregunta del caminante o el ciceroniano, y asi junto a los rasgos físicos se mencionan los morales o los que expresan la calidad de las mujeres.

El nombre tiene un sentido especial para los autores de los siglos XVI y XVII, pues, con reminiscencias medievales, el nombre sigue siendo "como imagen de la cosa de quien se dice o la misma cosa disfrazada en otra manera» según apunta Fray Luis de León ${ }^{18}$. De ahí que el propio nombre de Dulcinea haya merecido el interés de algunos estudiosos que han llegado a relacionarlo con el dulzor de la miel, apetecible por los osos, palabra que está incluida en el apellido de Dulcinea, del

14 Libro de Buen Amor, estrofas 1012-13.

15 El retrato de Zoraida describe las joyas que vestia: «más perlas pendian de su hermosísimo cuello, orejas y cabellos, que cabellos tenia en la cabeza. En las gargantas de los sus pies, que descubiertas a su usanza traía, traía dos carcajes, que asi se llamaban las manillas o ajorcas de los pies en morisco, de purísimo oro, con tantos diamantes engastados, que ella me dijo después que su padre los estimaba en diez mil doblas, y las que traía en las muñecas de las manos valian otro tanto" (I, 41).

16 La poetisa Hafsa ar-Rakuniyya se describe a si misma con los tópicos de la descripción de la mujer en la poesía modernista, con cuello de gacela, mirada embrujada, mejillas de rosa y dientes como perlas. M. J. Rubiera, Poesia femenina hispanoárabe, Madrid, 1989, p. 91.

S. TRELlES, "Rhetorical Canons and Female Portraits...". p. 158 y ss

18 A. REDONDO, "Del personaje de Aldonza Lorenzo al de Dulcinea del Toboso: algunos aspectos de la invención cervantina", Anales Cervantinos, 21, 1983, p. 10. 
Tob-oso ${ }^{19}$. El nombre de Marcela podria tener un significado muy preciso y buscado por Cervantes, quien parece que pudo darle ese nombre por Marcellina, la hermana de S. Ambrosio de Milán, a la que su hermano le dedicó el tratado De Virginibus ${ }^{20}$. Quiteria podría recibir su nombre de la Santa Quiteria del Libro de Buen Amor ${ }^{21}$. Leandra parece haber sido bautizada por Cervantes en honor a otra Leandra, protagonista de un poema italiano de Durante de Gualdo ${ }^{22}$.

No faltan las mujeres sin nombre, como el ama o la ventera, o aquellas que aparecen citadas como "la de..." (la mujer de..., la hija de...), forma típica de referirse a las mujeres en muchos documentos medievales; las más famosas la hija del ventero, la hija de doña Rodríguez, la hija de Diego de la Llana, o la mujer de Antonio Moreno. La sobrina, que aparece citada más de sesenta veces en la obra, solo aparece como Antonia Quijano al final del libro, cuando ya don Quijote está redactando su testamento y parece forzado a identificarla con nombre y apellido.

Las señas de identidad que comienzan con el nombre, seguirian con el estado social, la manera de vida y, en algunos casos, con la edad. Todas las mujeres estaban solteras, a punto de contraer matrimonio, o lo contraian en la obra. Buena parte de ellas son labradoras o hijas de ricos labradores, excepto algunas que son de familias hidalgas, o de alta alcurnia como la duquesa y la falsa condesa. En el medio de la casa ducal no podían faltar las dueñas, cuya misión de acompañar a las mujeres de las casas nobiliarias tiene un precedente literario singular en las dueñas del Poema de Mío Cid.

Mención especial requiere las referencias a la edad, por su peculiaridad y por las ideas medievales en relación con lo que podría considerarse edad ideal de las mujeres. Algunas llegaban a ser realmente hermosas a partir de los 14 años. La pastora Marcela lo fue "cuando llegó a edad de catorce a quince años" (I, 12); la hermosa Quiteria tenía 18 años cuando se iba a casar con Camacho el rico (II, 19), y en sus bodas danzaban «doncellas hermosísimas, tan mozas que al parecer ninguna bajaba de catorce ni llegaba a diez y ocho años" (II, 20); la ninfa que llega en

19 A. Redondo, "Del personaje de Aldonza Lorenzo al de Dulcinea...". Defiende este autor esa teoría, al tiempo que la relaciona con Melibea, palabra relacionada con miel. Los nombres de las protagonistas de estas obras habrian estado muy estudiados, y responderían en cierta medida a un conocimiento profundo de los autores de algunas obras medievales, entre las que cabria destacar el Libro de Buen Amor, o las serranillas del Marqués de Santillana.

${ }_{20}$ MCGaHA, M. D., "The sources and meaning of the Grisóstomo-Marcela episode in the 1605 "Quijote", Anales Cervantinos, 16, 1977, p. 47.

21 “la Quaresma católica dola a Santa Quiteria» (estrofa 1312). Una copla relaciona a Santa Quiteria con el matrimonio, tema con el que también está relacionada la joven Quiteria que iba a casarse con el rico Camacho:

"Santa Quiteria bendita,

la tenemos que casar,

con San Gil de Arrancacepas,

"quisió" que resultará"

22 Obra publicada en 1508, debió servir de inspiración a Cervantes según F. Marquez Villanueva, Personajes y temas del Quijote, p. 80 y ss. 
el carro triunfal para decir cómo desencantar a Dulcinea «traía el rostro cubierto con un transparente y delicado cendal, de modo, que, sin impedirlo sus lizos, por entre ellos se descubria un hermosísimo rostro de doncella; y las muchas luces daban lugar para distinguir la belleza y los años, que, al parecer, no llegaban a veinte ni bajaban de diez y siete» (II, 35); «la niña Antonomasia llegó a edad de catorce años, con tan gran perfeción de hermosura, que no la pudo subir más de punto la naturaleza.» (II, 38). La doncella Altisidora, que se enamora de don Quijote se define a si misma asi:

Niña soy, pulcela tierna;

mi edad de quince no pasa;

catorce tengo y tres meses

te juro en Dios y en mi ánima. (II, 44).

La edad de las mujeres, en concreto su especial hermosura o perfección entre los 14 y 18 años, era una idea que hundía sus raíces en la Edad Media. Unos versos de Carvajal, poeta de la corte de Alfonso $\mathrm{V}$ el Magnánimo, apuntan incluso a una edad más temprana como la más apetecible para contraer matrimonio con las mujeres:

La perfección de nosotras mujeres, es de los trece fasta los quinse años: con estas se toman suaves plaseres et todas las otras son llenas de engaños

Esta alabanza de la juventud de las mujeres, estaría en línea con un divertido proverbio árabe: "Cuando veas a una vieja, invoca el nombre de Dios y corre» ${ }^{23}$.

Siguiendo los modelos citados, del De inventione o del Quijote, a los caracteres objetivos de nombre, edad y estado social, habria que añadir lo que se denominaría la calidad. La pastora Marcela «hermosa el alma como el cuerpo tiene» (I, 14); Luscinda era "la más hermosa y más discreta mujer del mundo" (I, 24); Dorotea "era tan hermosa, recatada, discreta y honesta, que nadie que la conocia se determinaba en cuál destas cosas tuviese más excelencia ni más se aventajase" $(\mathrm{I}, 24)$, y Camila era muy hermosa, pero además admirable por su «sagacidad, prudencia y mucha discreción" (I, 34).

Discreción, prudencia, recato y honestidad son algunos de los valores destacados en las mujeres del Quijote, en concreto de las que aparecen como individualidades. Todas ellas son cualidades enfatizadas en las mujeres de la Edad Media, en cuyo tiempo se fueron construyendo esos valores. Prudencia y discreción exigian de la mujer ser comedida en sus palabras y gestos. De esa manera el silencio, cuya importancia habia destacado la Iglesia desde principios del siglo II, se colocaba en primer plano, como algo que la mujer había de imponer-

${ }^{23}$ Writing the feminine. Women in Arab Sources, ed. M. Marín and R. Deguilhem, London, 2002.p. 45. 
se a si misma, pues de natural se la consideraba parlanchina o deslenguada ${ }^{24}$. Algunos gestos, como la risa, también se consideraban inapropiados de las mujeres: "Bien parece la mesura en las fermosas, y es mucha sandez además la risa que de leve causa procede; pero non vos lo digo porque os acuitedes ni mostredes mal talante... " dice don Quijote a las mozas de la venta que no pueden contener la risa al verle llegar. Seguía don Quijote ideas medievales, como puede verse en este fragmento de la regla que San Leandro redactó para su hermana Florentina: “En la risa aparece lo que es el corazón de una virgen, pues nunca reirá con descaro si tuviere un corazón casto... Huye, por tanto, de la risa, hermana mía, como de una locura y trueca en llanto toda la alegría de este mundo".

El recato también formaba parte de la prudencia y discreción de una dama, aunque venia exigido por la virtud de la templanza, que requería de las mujeres comedimiento y sobriedad, especialmente en lo relacionado con los placeres del tacto, y en concreto con la concupiscencia. La honestidad, uno de los valores esenciales de las mujeres se conseguía con las virtudes de la templanza y de la fortaleza; era uno de los valores más ensalzados y básicos en la sociedad medieval, con una importante cimentación elaborada por la Iglesia cristiana desde los primeros siglos de su existencia.

El recato reclamaba de la mujer pasar lo más desapercibida posible, no destacar, no ser visible; para ello tenía que evitar argucias, como maquillajes, tintes u otras cosas. Eso iba en contra de la esencia femenina, pues como dice Anselmo, en el cuento del curioso impertinente, "las mujeres suelen ser aficionadas, y más si son hermosas, por más castas que sean, a esto de traerse bien y andar galanas" (I, 33). Muestras varias hay en el Quijote de ese afán de las mujeres por mejorar su apariencia. La pastora Torralba, cuando sale a buscar a su amado Lope por los caminos, viajaba «con unas alforjas al cuello, donde llevaba, según es fama, un pedazo de espejo y otro de un peine, y no sé qué botecillo de mudas para la cara" (I, 20). Parece que no faltaban las "depiladoras": "puesto que hay en Candaya mujeres que andan de casa en casa a quitar el vello y a pulir las cejas y hacer otros menjurjes tocantes a mujeres, nosotras las dueñas de mi señora por jamás quisimos admitirlas, porque las más oliscan a terceras, habiendo dejado de ser primas» (II, 40). La referencia muestra la relación entre afeites y mejunjes y la deshonestidad, con esa velada indicación de que quienes se dedican al oficio son "terceras", es decir, que se dedicarian al oficio de la tercería, mediación o alcahuetería, tan bien ejercido por la famosa Celestina.

No faltaban, sin embargo, mujeres que utilizando argucias conseguian engañar a los hombres, como se indica en el poema que recita Antonio, en la aventura de los cabreros:

24 La prudencia, uno de los valores más apreciados, se divulga de manera especial por parte de los escritores del Siglo de Oro, pero forma parte del ideario medieval. La obra de Tirso de Molina. La prudencia en la mujer, tiene como protagonista a la reina María de Molina. 
Teresa del Berrocal.

Yo alabándote, me dijo:

«Tal piensa que adora a un ángel,

y viene a adorar a un jimio.

Merced a los muchos dijes

$Y$ a los cabellos postizos,

$Y$ a hipócritas hermosuras,

Que engañan al Amor mismo" $(I, 11)$

El rechazo de los elementos para aumentar la belleza era un discurso utilizado por la Iglesia desde hacia siglos. Es muy ilustrativa a este respecto la regla monástica de San Leandro antes citada, donde se afirma que "El cuerpo adornado excita", y una mujer cristiana y honesta no puede atraer hacia ella las miradas concupiscentes de los hombres, pues «tratar de gustar a la mirada ajena es pasión de meretriz».

El recato exigía a las mujeres mostrarse lo menos posible, y para ello debían de permanecer en casa al menos que tuvieran que salir para cumplir con alguna obligación tan importante como la de ir a misa. Solo las pobres salian porque tenían que trabajar, pero las damas no necesitaban ir a la calle, idea y práctica que también hunden sus raíces en el Medievo. Ir a la Iglesia era una obligación, aunque también una devoción, lo que se consideraba otro de los valores femeninos.

Ser devota en general o tener devoción a la virgen en particular, sería una de las virtudes a destacar en una mujer. Varias citas se podrian señalar como ejemplo de la religiosidad femenina en el Quijote, y en concreto de la devoción a la Virgen, cuya imagen tenía un lugar en las alcobas, como en la de Dorotea. Fue la imagen testigo del matrimonio de ésta con don Fernando, quien además se fija en la imagen de la Virgen para convencer a Dorotea que le acepte como esposo: «aquí te doy la mano de serlo tuyo, y sean testigos desta verdad los cielos, a quien ninguna cosa se asconde, y esta imagen de Nuestra Señora que aqui tienes" $(1,28)$. La hija del morisco Ricote, Ana Félix «iba llorando y abrazaba a todas sus amigas y conocidas y a cuantos llegaban a verla, y a todos pedía la encomendasen a Dios y a Nuestra Señora su madre» (II, 54)

El tiempo del Quijote mantenía el modelo de la Virgen María, exaltado extraordinariamente desde el siglo xII, como el modelo de honestidad ${ }^{25}$. La Virgen Maria tiene su "altar" especial en el episodio del cautivo, con el amor que la mora Zoraida tenía a Lela Marién ${ }^{26}$. La devoción a la Virgen, en concreto de mujeres musulmanas tiene un antecedente medieval en las historias cuya protagonista es una "morica garrida" que enamorada de un cristiano se convierte al cristianismo ${ }^{27}$.

25 La devoción a la Virgen era compartida por mujeres y hombres: "Soy devoto de Nuestra Señora y confio siempre en la misericordia infinita de Dios Nuestro Señor", le dice don Diego de Miranda a don Quijote (II, 16).

26 "¿qué demonios lleva en el pecho que le incitan a ir contra nuestra fe católica? Aơvierta, mal haya yo, que aquella es procesión de diciplinantes, y que aquella señora que llevan sobre la peana es la imagen benditisima de la Virgen sin mancilla" $(I, 52)$.

27 F. Márouez VILlanueva, Personajes y temas del Quijote, p. 106 y ss 
Algunas de estas mujeres tenian casi como único mérito el de su devoción, pues en algunos de los ejemplos, y es muy destacado el de Zoraida, las protagonistas se saltaban uno de los valores esenciales de las mujeres, el de la obediencia, en concreto la obediencia al padre. Los hombres de Iglesia habían establecido la obediencia de las hijas hacia sus padres como uno de los más importantes deberes femeninos. Un libro del dominico francés Vincent de Beauvais (1190-1264) dedicado hacia 1250 a la reina Margarita, De eruditione filiorum nobilium, destacaba, entre otras, la virtud de la obediencia filial ${ }^{28}$.

Ser obedientes, devotas o invisibles eran grandes valores, de manera que parece que las mujeres eran valoradas fundamentalmente por lo que no hacian, más que por lo que hacían: se les exigía mantenerse en silencio, no salir a la calle ni dejarse ver, no actuar a no ser que fuera la voluntad de los padres, esposos o hermanos de la familia.

Los deberes familiares, en concreto la obligación hacia los varones, exigian de las mujeres el mantenimiento de la honestidad, pues la pérdida del honor o de la honra alcanzaba al resto de la familia. En Don Quijote hay citas al valor primordial de la honestidad: "La honesta y casta mujer es arminio, y es más que nieve blanca y limpia la virtud de la honestidad" (1,33), asi como al problema que planteaba a los varones de la familia el que una mujer la perdiera: "teniéndose por deshonrada, te toca a ti, como a cosa tuya, su mesma deshonra" $(I, 33)$. "Y de aquí viene que, como la carne de la esposa sea una mesma con la del esposo, las manchas que en ella caen, o los defectos que se procura, redundan en la carne del marido, aunque él no haya dado, como queda dicho, ocasión para aquel daño... el marido es participante de la deshonra de la mujer, por ser una mesma cosa con ella.» (II, 33). Esa pérdida de la honra o el honor familiar hunde también sus raíces en la Edad Media, etapa en la que se elabora todo el discurso sobre el valor de la castidad y la virginidad de las mujeres, que lleva a valorarlas por los niveles de posible castidad que mantengian en su vida. De ahi que las solteras y monjas son las que tenían más valor, seguidas de las viudas, y en último lugar las casadas. Esos valores se muestran también en el Quijote, donde se afirma «la ventaja que hace una dueña doncella a una dueña viuda" (II, 36). Cervantes, sin embargo, no parece que tenga completamente claro ese punto, y ante las dudas encontraba la solución mejor para las mujeres: servir el camino de las normas aceptadas o el orden natural.

\section{PAPELES DE MUJER: AMOR Y MATRIMONIO}

Le prometían el verse ayuntado en santo y debido matrimonio con su querida Dulcinea del Toboso, de cuyo felice vientre saldrían los cachorros, que eran sus hijos, para gloria perpetua de la Mancha

Don Quijote I, 46

${ }^{28}$ Paulette L'HeRmite-LeCLerCQ, L'Église et les femmes dans I'Occident chrétien des origines à la fin du Moyen Age. Brepols, 1997, p. 252. 
Pocas son las veces que aparece alguna mención al posible matrimonio de don Quijote con su amada Dulcinea. Muchas, por el contrario, son las citas del amor del caballero hacia su querida dama. El amor aparece continuamente en el Quijote, porque el protagonista es un personaje enamorado; su amor responde a muchas de las características del amor cortés. Dulcinea es su dama, y a ella tiene que hacer llegar sus aventuras, su fuerza, su valor, su bondad, sus buenas cualidades en general. Aunque el amor no lleve a don Quijote al matrimonio, buena parte de las mujeres de la obra terminan casándose, de ahi que pueda afirmarse que ambos asuntos, matrimonio y amor, sean temas estrella del Quijote.

Amor y matrimonio son los dos caminos por los que ha de pasar una mujer de acuerdo con el orden natural aceptado por la sociedad cristiana durante muchos siglos. Solo la vocación religiosa puede dispensar a la mujer de esos dos caminos que le ha marcado la naturaleza. Muchas de las mujeres del Quijote son mujeres enamoradas, y la mayoría terminan casándose con los hombres a quienes aman. El amor de esas mujeres no es, sin embargo, el amor cortés, tema esencial presentado con sarcasmo en la obra, sino el amor de unas mujeres independientes que eligen a los hombres con quienes casarse.

La forma de presentar el tema del amor es aparentemente contradictorio. El amor conducía a las mujeres del Quijote al matrimonio, lo que no era convencional en la sociedad de su época, ni lo aceptaba el propio Cervantes. Las historia de amor presentan a mujeres independientes, capaces de tomar la decisión de seguir el camino que ellas trazan y no el que otros trazan por ellas, en última instancia recordarían a Melibea, que con toda frescura busca la relación con el hombre que ama.

El otro tipo de amor, el amor que el protagonista siente por su dama, el amor cortés, se presenta en forma paródica y ridiculizada. No serviría el tema del amor cortés como justificación de la supervivencia de elementos medievales durante el Renacimiento ${ }^{29}$, pero al menos permite reconocer en ese tipo de amor rasgos del amor lícito que Cervantes acepta para la mayor parte de sus protagonistas femeninas. Cervantes parece conocer bien las características del amor cortés, y así lo dibuja en los sentimientos de don Quijote y en el comportamiento hacia su dama, y de la dama hacia él; al comienzo de la novela se dirige a ella diciendo: "princesa Dulcinea, señora de este cautivo corazón!, mucho agravio me habedes fecho en despedirme y reprocharme con el riguroso afincamiento de mandarme no parecer ante la vuestra fermosura. Plégaos, señora, de membraros de este vuestro sujeto corazón, que tantas cuitas por vuestro amor padece» $(l, 2)$. El desdén con el que Dulcinea trata a don Quijote se muestra a lo largo de toda la obra, y se califica de "sequedad" (II, 59). Don Quijote se muestra continuamente fiel, y ante los asaltos o tentaciones de otras damas, él mantiene su fidelidad a Dulcinea, haciendo gala de su caballería.

C. S. LEwIS, Allegory of Love, Oxford, 1936, citado por H. Iventosch, "Cervantes and Courtly Love: The Grisostomo-Marcela Episode of Don Quixote", PMLA (Publications of the Modern Language Association), 89, 1 (Jan. 1974), p. 64. 
El talante caballeroso de don Quijote no es común en algunos de los hombres que aparecen en la novela, aunque los amantes de las mujeres enamoradas son en su mayor parte bondadosos y respetuosos con ellas, incluso el infame Vicente de la Roca, que le quita todo a la pobre Leandra, menos la honra, el bien más preciado para aquel tiempo. Las locuras de amor que llevaban a la perdición de las mujeres son en buena medida consecuencia de los errores femeninos, aunque son pocas las mujeres que los cometen.

Cervantes tenia un alto concepto del amor, fuera de todo impudicia, hasta decir "donde hay mucho amor no suele haber demasiada desenvoltura" (II, 65). Cervantes reconoce a la mujer el derecho a enamorarse ${ }^{30}$; la mayor parte de la espléndida galeria de mujeres del Quijote, son amantes de amores lícitos, honestos, cristianos. El amor de Dorotea es un amor sano, no lujurioso, dirigido al matrimonio, aceptado en una palabra, "representa el del amor sellado por el matrimonio sobre la lujuria y la carnalidad del sexo» ${ }^{31}$. El amor de Luscinda hacia Cardenio es, sin duda, otro amor limpio y puro, lo mismo que el de Quiteria hacia Basilio. El amor de Zoraida hacia el cautivo no es ni siquiera amor, es interés porque la ayude a llevarla a tierra de cristianos. Casi todas las historia son de amores hermosos, pues no considera dignos de contarse los amores que no son hones$\operatorname{tos}^{32}$.

Se considera un avance progresista de Cervantes el proponer el matrimonio por amor en muchas de las protagonistas enamoradas ${ }^{33}$, sin embargo en los matrimonios por mutuo consentimiento que aparecen en el Quijote como los de Dorotea y don Fernando, Luscinda y Cardenio, o Quiteria y Basilio, se ven más bien las reminiscencias medievales del consensus matrimonium fecit de los teólogos cristianos del siglo XII. Las leyes castellanas, Fuero Juzgo, Siete Partidas y Leyes de Toro, reflejaban la existencia de los matrimonios por mutuo consentimiento, celebrados clandestinamente, y los rechazaban por conveniencias sociales, imponiendo penas a quienes se unieran de ese modo. Cervantes muestra este modelo de matrimonio sin posicionarse respecto a él, y aunque parece aceptarlo, no deja de plantear algunas de las ideas convencionales de su tiempo, como no parecerle adecuado mezclar matrimonio y amor.

Aunque la mayor parte de los matrimonios de sus historias se han efectuado por mutuo consentimiento de los amantes, de forma "clandestina", irregular para las ideas convencionales de la época, expone las ideas del matrimonio tridentino tal como la Iglesia lo exigía para los cristianos. Es con motivo de la estratagema

30 En este tema se ha dicho de Cervantes: «Hasta entonces nadie ha defendido en España la libertad de amar de la mujer como él», O. LOPEZ FANEGO, "Algunas reflexiones acerca de la mujer en Montaigne y en Cervantes", Anales Cervantinos, 19, 1981, p. 113.

31 F. Márouez Villanueva, Personajes y temas del Quijote, p. 63.

32 F. Marouez VIllanueva, Personajes y temas del Quijote: "tmpulsado por el platonismo en tanta medida quizá como por la ortodoxia católica. Cervantes no concede validez artística a ningún amor deshonesto y, según ha notado $\mathrm{M}$. Bataillon, se halla visibiemente ligado a la renovada atención concedida por Erasmo y el humanismo cristiano al sacramento del matrimonion, pp. 63-4.

33 S. E. Trachman, Cervantes' Women of Literary Tradition, Nueva York, 1932, p. 37. 
ideada por Basilio para casarse con su amada Quiteria a punto de contraer matrimonio con el rico Camacho, cuando don Quijote dice: "Si todos los que bien se quieren se hubiesen de casar - dijo don Quijote-, quitariase la elección y juridición a los padres de casar sus hijos con quien y cuando deben, y si a la voluntad de las hijas quedase escoger los maridos, tal habría que escogiese al criado de su padre, y tal al que vio pasar por la calle, a su parecer bizarro y entonado, aunque fuese un desbaratado espadachín; que el amor y la afición con facilidad ciegan los ojos del entendimiento, tan necesarios para escoger estado, y el del matrimonio está muy a peligro de errarse, y es menester gran tiento y particular favor del cielo para acertarle. Quiere hacer uno un viaje largo y, si es prudente, antes de ponerse en camino busca alguna compañia segura y apacible con quien acompañarse. Pues ¿por qué no hará lo mesmo el que ha de caminar toda la vida hasta el paradero de la muerte, y más si la compañia le ha de acompañar en la cama, en la mesa y en todas partes, como es la de la mujer con su marido?" (II, 19). Este párrafo es una auténtica contradicción con respecto a lo que hacen las mujeres enamoradas de sus historias. Pero esto es habitual en Cervantes, que refleja dos realidades, la presente y la pasada, y en este caso del matrimonio, aunque la pasada pueda parecer más "progresista", es en realidad la heredada de la Edad Media.

En efecto, no parece adecuado hablar de «progresismo» o «modernismo» en la posición de Cervantes acerca del matrimonio, sus ideas están en la línea de apoyar «el matrimonio cristiano como uno de los cimientos del orden social» ${ }^{34}$. Se inclina por la indisolubilidad: "La de la propia mujer no es mercaduria que una vez comprada se vuelve o se trueca o cambia, porque es accidente inseparable que dura lo que dura la vida. Es un lazo que, si una vez le echáis al cuello, se vuelve en el nudo gordiano que, si no le corta la guadaña de la muerte, no hay desatarle» (II, 19), se opone al amancebamiento

No te quiero yo a montón,

Ni te pretendo y te sirvo

Por lo de barragania;

Que más bueno es mi designio. $(1,11)$

y propugna la idea de llevar la carga del matrimonio con resignación cristiana:

Coyundas tiene la Iglesia

Que son lazadas de sirgo;

Pon tú el cuello en la gamella;

Verás como pongo el mío. $(1,11)$

El matrimonio y el amor como una carga es lo que lleva a la pastora Marcela a abandonar su casa y a vivir en un ambiente pastoril, en el que solo tenía relación

34 A. K. Forcione, Cervantes' Christian Romance: a Study of Persiles y Sigismunda, Princeton, 1972 , p. 119 
con otras mujeres. Aunque no vive en la clausura de un convento, como hubieran hecho las mujeres medievales que buscaban libertad, vive de forma bastante similar, libre, independiente y haciendo lo que le placia, lejos del alcance de los varones de su familia o de los hombres que la pretendian para casarse; su forma de vida recuerda al de las monjas de un monasterio, con la diferencia de que en vez de vivir en un espacio cerrado, vivia al aire libre. Pocas veces Cervantes pone a sus heroínas en un convento, parece tener una actitud anti-monástica, quizás por considerar que el convento frenaba las posibilidades de desarrollo de las mujeres, aunque parece haberse demostrado que muchas mujeres buscaban la vida conventual para liberarse del poder masculino dentro de la familia, constituyéndose así algunos monasterios medievales en reductos femeninos de libertad.

Sin estar recluida en un convento, Marcela podria ser buen modelo de la mujer libre, la mujer "esquiva", que desafia el orden natural, al que teme y considera una carga. Se sale de ese modelo de mujer en la medida que no es vencida por ningún hombre, como solía ocurrir con las mujeres rebeldes, al contrario, la defensa de su libertad contra las acusaciones de ser culpable de la muerte de Grisóstomo, la convierten en heroina invencible. La mujer esquiva, independiente y rebelde, es el tipo de mujer que mejor sirve para ilustrar la naturaleza de la actitud de la sociedad del siglo XVII hacia las mujeres, y los aspectos misóginos o pro-feministas de esa sociedad $^{35}$.

\section{QUERELLA DE LAS MUJERES: MISOGINIA Y «FEMINISMO»}

\section{Allí me dijo él que vio la vez primera a aquella} enemiga mortal del linaje humano" $(l, 13)$.

La enemiga mortal del línaje humano a la que se referían estas palabras de Ambrosio era la pastora Marcela, la "enemiga mía hermosa", la joven doncella que no había aceptado el orden natural que obligaba a las mujeres a someterse a unos determinados modos de conducta. Ese era en realidad el problema que planteaba Marcela a los hombres que la rodeaban, no acomodarse a las reglas sociales del momento; su forma de vida no les podia hacer daño; en realidad no podia perjudicar a nadie su vida modélica cristiana: vivía con la virginidad, pobreza y austeridad predicadas por el cristianismo.

El modelo de Marcela no es, sin embargo, denostado por Cervantes, y aunque permite a alguno de los personajes decir palabras duras contra esta mujer, el discurso que pone en labios de la propia Marcela para defenderse de la acusación de haber provocado la muerte de Grisóstomo, y las palabra de don Quijote sobre ella, dejan translucir la simpatía de Cervantes por este personaje femenino: "Ella

35 M. MCKENDAICK, "The "mujer esquiva". A Measure of the Feminist Sympathies of SeventeenthCentury Spanish Dramatists". Hispanic Review, vol. 40, 2 (Spring, 1972), pp. 162-197. 
ha mostrado con claras y suficientes razones la poca o ninguna culpa que ha tenido en la muerte de Grisóstomo, y cuán ajena vive de condescender con los deseos de ninguno de sus amantes; a cuya causa es justo que, en lugar de ser seguida y perseguida, sea honrada y estimada de todos los buenos del mundo, pues muestra que en él ella es sola la que con tan honesta intención vive". Aunque es poco probable que Cervantes conociera a Cristina de Pisan, la historia de la pastora Marcela respondería a estas palabras de la autora francesa: «Estoy segura de que son muchas las mujeres a quienes la belleza no impide saber defenderse de las trampas y los engaños de la seducción masculina" ${ }^{36}$.

Sin embargo, el tema de la mujer culpable de los males de los hombres es tratado con cierta ambigüedad, como el tratamiento del tema de la honra, y el de otros aspectos relacionados con las mujeres. Cervantes se presenta en ocasiones como aceptando las convenciones de su tiempo, y otras parece estar más cercano a las ideas de escritoras como Cristina de Pisan, que le precedió doscientos años, o como su contemporánea María de Zayas, o su contemporáneo Michel de Montaigne, que no aceptaban ni la culpabilidad de las mujeres violadas ni el deshonor de un marido engañado.

La ambigüedad de Cervantes queda de manifiesto en el tratamiento de algunas mujeres, y en concreto en el de esta mujer esquiva que es Marcela; Cervantes sigue su típica dicotomía de contraponer dos aspectos o dos modelos, y de «no comprometerse en forma integral con ninguna doctrina, el no admitir ninguna tesis sin formular a la vez alguna reserva o prestar su atención o simpatía al punto de vista contrario" ${ }^{37}$. De esa manera crea personajes femeninos adorables al lado de mujeres de mala conducta, dibuja retratos femeninos bellisimos al lado de otros de mujeres zafias, incluye citas en las que las mujeres aparecen como ángeles, y citas en las que aparecen como demonios. Expone en diferentes modelos femeninos la dicotomía maldad-bondad de la tradición judeo-cristiana en relación a la mujer. De hecho su táctica consiste en hablar muy bien de algunas mujeres en particular, y guardar los vituperios para hablar de las mujeres en general.

Con motivo de la historia de la Torralba dice: "Esa es natural condición de mujeres -dijo don Quijote-: desdeñar a quien las quiere y amar a quien las aborrece» (I, 20). La acción de Leandra, la joven que abandona la casa paterna para huir con el soldado, no se debe a un acto de ignorancia "sino a su desenvoltura y a la natural inclinación de las mujeres, que, por la mayor parte, suele ser desatinada y mal compuesta" $(1,51)$; el ama dice "mis gallinas que no me dejarán mentir. -Eso creo yo muy bien - respondió el bachiller-; que ellas son tan buenas, tan gordas y tan bien criadas, que no dirán una cosa por otra si reventasen" (II, 7), en contra de la fama de mentirosas de las mujeres; el Caballero del Bosque le cuenta aventuras a don Quijote, y entre ellas el desafio a la giganta de Sevilla, llamada la Giralda que "sin mudarse de un lugar, es la más movible y voltaria mujer del mundo"

36 La ciudad de las damas, Madrid, 1995, p. 204.

37 F. Marouez Villanueva, Personajes y temas del Quijote, p. 64. 
(II, 14); don Quijote dice que «las armas de los togados son las mesmas que las de la mujer, que son la lengua" (II, 32). Claudia Jerónima, al contarle su caso a don Quijote le dice «no hay mujer, por retirada que esté y recatada que sea, a quien no le sobre tiempo para poner en ejecución y efecto sus atropellados deseos" (II, 60). $Y$ hace un comentario peyorativo también al decir que "las mujeres de ordinario son presurosas y amigas de saber" (II,62), puesto que no se trata del saber en un buen sentido, sino en el sentido del cotilleo y chismorreo. «Fortuna es una mujer borracha y antojadiza, y, sobre todo, ciega, y así, no vee lo que hace, ni sabe a quien derriba ni a quien ensalza» (II, 66).

De todas estas citas sale un concepto claramente misógino de las mujeres: débiles de carácter, desobedientes, caprichosas, cotillas, parlanchinas, mentirosas, volubles. Además Cervantes retrata a las mujeres como ignorantes, que no leen libros o que queman libros, como el "ama de Satanás" (II, 2) y la sobrina, aunque no olvida señalar que son los hombres quienes no las dejan leer, al menos que lean libros piadosos. La única que lee, o que ha leido la primera parte del Quijote, ha sido la Duquesa, a quien retrata no precisamente como una buena mujer. Sus obras denuncian la impiedad de su alma, y Cervantes tiene en mente la idea de que son las obras, más que la casta o el linaje, las que conceden honra u honor; así don Quijote dice que Dulcinea "es hija de sus obras» (II, 32), y de Marcela dice Cardenio "Lo que levantó tu hermosura han derribado tus obras: por ella entendí que eras ángel, y por ellas conozco que eres mujer» $(1,22)$.

Pero si hay un sentido peyorativo en las obras de Marcela, hay un sentido positivo en la valoración de las obras de otras mujeres. De forma positiva estima a la caritativa ventera, a su hija y a Maritornes, ese trio de mujeres de la venta, que recuerdan en cierto modo a las tres Marías, en especial si se compara a Maritornes con Magdalena ${ }^{38}$; la simpatía de Cervantes por Maritornes se muestra en algunos pasajes, como cuando justifica su oficio: "cuéntase de esta buena moza que jamás dio semejantes palabras que no las cumpliese, aunque las diese en un monte y sin testigo alguno, porque presumía muy de hidalga, y no tenía por afrenta estar en aquel ejercicio de seguir en la venta; porque decía ella que desgracias y malos sucesos la habian traído a aquel estado" $(1,16)$. Maritornes, a imagen de la Magdalena, es una mujer que representa en sí misma la dicotomía maldad-bondad antes citada ${ }^{39}$. Con "sombras y dejos de cristiana" $(I, 17)$, rezando el rosario, y cumpliendo siempre la palabra dada, Maritornes responde a un refrán recogido ya a finales del siglo XVI: "Ser puta y buena mujer, ¿cómo puede ser, señor bachiller?» ${ }^{40}$.

No parece preocuparle mucho a Cervantes la libertad sexual de algunas de las mujeres del Quijote, pero en vez de denostar a las pecadoras, las justifica y busca p. 78

38 A. Rodriguez y J. Ruzicka, "¿Ecos de la Magdalena en Maritornes?", Romance Notes, 30, 1989.

${ }^{39}$ La figura de Maritornes presentada como humana y bondadosa se destaca en M. K. de Trinker. Las mujeres en el Don Quijote de Cervantes comparadas con las mujeres en los dramas de Shakespeare, México, 1938, p. 40

${ }^{40} \mathrm{H}$. Nuñez, Refranes y proverbios en romance, Valladolid, 1592. 
una salida para ellas, que no es generalmente la del convento. A una de las que manda al convento es a Camila, víctima de la curiosidad de su esposo. En ese alineamiento con las mujeres, Cervantes, como su coetáneo Montaigne, exculpan a las mujeres de algunos de sus fallos, por ser en realidad los hombres quienes las empujan a ellos. Montaigne descalifica a los maridos que emprendían alguna investigación obsesiva acerca de la conducta de su esposa, pues «la curiosidad es mala siempre, pero perniciosísima en esto " ${ }^{41}$, lo que demuestra Cervantes en los capítulos de la novela del curioso impertinente.

La misoginia de la sociedad de finales de la Edad Media y comienzos de la Moderna no se había plasmado de manera mayoritaria entre los escritores castellanos. En la querella de las mujeres se puede encontrar un número mayor de escritores favorables a las mujeres, que escritores misóginos. Por ello habría que pensar que la concepción de la mujer que tenía Cervantes, como la de otros escritores de su tiempo, les habria llegado por una doble vía, la vulgar, en la que las mujeres no eran especialmente apreciadas, y la culta, en la que no destacaban las ideas misóginas.

Esas dos tradiciones están plasmadas en el Quijote hasta el punto que podria decirse que en la obra se reproduce la "querella de las mujeres»; en efecto, Cervantes expone opiniones enfrentadas a veces, como consecuencia de su intención de situarse "unas veces en el plano de lo ideal deseable y otras, con mayor o menor prudencia, o con toda franqueza, según los casos, en el de la realidad concreta y circunstanciada de la vida diaria de su época” ${ }^{42}$. De esa manera podriamos decir que su postura en relación con las mujeres tiene mucho de tradicional y algo de moderno, mucho de medieval y algo de renacentista; expone comportamientos medievales en la mayoría de las mujeres, y las permite transgredirlos. De la posición de Cervantes respecto al papel de la mujer ha dicho Américo Castro: «la mujer es para Cervantes el más tremendo imperativo vital, contra el que suelen estrellarse los poco avisados ${ }^{43}$.

\section{CONCLUSIÓN: REFLEJOS DE MEDIEVALISMO EN EL ESPEJO DE LAS MUJERES}

De acuerdo con el Diccionario de la Real Academia de la Lengua, deconstrucción es el «desmontaje de un concepto o de una construcción intelectual por medio de su análisis, mostrando así sus contradicciones y ambigüedades". Esta ha sido la idea fundamental de este artículo: analizar algunos de los aspectos más significativos acerca de las mujeres en el Quijote, para tratar de mostrar las contradicciones, ambigüedades o dicotomías de Cervantes, y reconsiderar la idea ex-

41 De los Ensayos de M. de Montaigne, citado por O. LOPEZ FANEGo, «Algunas reflexiones acerca de la mujer en Montaigne y en Cervantes", p. 109.

42. O. López FANEGO, "Algunas reflexiones acerca de la mujer en Montaigne y en Cervantes", p. 107.

4.3 A. Castro, El pensamiento de Cervantes, p. 368. 
tendida entre algunos de sus estudiosos acerca de la modernidad y progresismo de sus puntos de vista.

Se ha partido de la hipótesis de que hay importantes pervivencias medievales en los retratos de mujer que aparecen en el Quijote, y no solo en los retratos físicos, sino en los morales y en los papeles que se atribuyen a las mujeres: el amor y el matrimonio. En la búsqueda de antecedentes medievales, se han podido deconstruir algunos de los conceptos más aceptados, en concreto los relacionados con el amor, el matrimonio o la honestidad, y se han podido ver modelos femeninos medievales reflejados en varias mujeres del Quijote.

Las lecturas del Quijote se han hecho desde observatorios tan diversos que un mismo personaje o una misma institución se han visto de maneras bien diferentes. Una lectura sin perspectiva ideológico-cristiana puede llevar a ver en Zoraida un monstruo odioso ${ }^{44}$, o, por el contrario, una "rosa de pasión y de ternura» ${ }^{45}$, o una heroína ${ }^{46}$ cuyas acciones se rigen por el criterio de que el fin justifica los medios ${ }^{47}$. Una lectura bajo la perspectiva de género, puede ver en el Quijote "una nutrida representación de textos de sabor misógino" "48, o un Cenvantes con simpatías hacia la mujer ${ }^{49}$, o indiferente ${ }^{50}$. Una lectura con una perspectiva medieval permite también una visión diferente, pues algunos de los aspectos interpretados como parte del progresismo de Cervantes (el matrimonio, por ejemplo), pueden verse como reflejos de la sociedad medieval más que como avances de la sociedad renacentista.

En la galería de mujeres que aparecen en el Quijote pueden verse de forma general caracteristicas de las mujeres de la Edad Media, como la presencia del binomio buena-mala, o los valores y papeles que se les atribuyen. Pueden verse de forma particular modelos medievales, literarios o históricos, algunos de producción hispana como la Cava Rumía, Doña Urraca o Jarifa, y otros europeos, del roman artúrico o del carolingio, como Ginebra, Belerma o Iseo ${ }^{51}$. En algunas de las mujeres creadas por Cervantes se pueden encontrar claros reflejos de antecesoras medievales aun sin nombrarlas. La pastora Marcela recibe su nombre, como se dijo antes, de Marcellina la hermana de san Ambrosio de Milán; algunos aspectos de su vida, ser huérfana que vive con un tío clérigo y que propone un tipo de vida libre, recuerdan retazos de la vida de Eloísa; y además es llamada "dulce enemiga", como la "dolce nemica" de Petrarca ${ }^{52}$. El personaje literario más presente en esta obra cervantina, tampoco aparece nombrado: Melibea.

${ }^{44}$ G. CIRot, Le "Cautivo" de Cervantes et Notre-Dame de Liesse, pp. 381-382.

45 C. Espirsa, Al amor de las estrellas (Mujeres del Quijote), Madrid, 1916.

46 M. C. RutA, "Zoraida: los signos del silencio en un personaje cervantino", Anales cervantinos, 21. 1983, p. 131

47 S. E. Trachman, Cervantes' Women of Literary Tradition, p. 41, nota 2.

4k F. Marquez VILlanueva, Personajes y temas del Quijote, p. 91.

${ }^{49} \mathrm{O}$. LOPEZ FANEGO, "Algunas reflexiones acerca de la mujer en Montaigne y en Cervantes.

50 S. E. Trachman. Cenvantes' Women of Literary Tradition, p. 1 y ss.

5 Las gestas francesas de tema carolingio sirvieron de inspiración de algunas de las mujeres o episodios del Quijote, tal es el caso de Leandra, F. Marouez VILlanueva, Personajes y temas del Quijote, p. 86.

52 H. IVENTOSCH, "Cervantes and Courtly Love: The Grisostomo-Marcela Episode of Don Quixote", p. 69. 
Las citas de mujeres o personajes medievales se encuentran, sin embargo, con cierta frecuencia, especialmente al buscar relaciones o antecedentes para algunos de los personajes femeninos. Buen ejemplo es Luscinda, «la más hermosa y más discreta mujer del mundo; y quisiera yo, señor, que vuestra merced le hubiera enviado, junto con Amadís de Gaula, al bueno de Don Rugel de Grecia, que yo sé que gustara la señora Luscinda mucho de Daraida y Garaya, y de las discreciones del pastor Darinel y de aquellos admirables versos de sus Bucólicas" (I, 24). Luscinda enamora a don Fernando, cuando éste la ve «en sayo" «a la luz de una vela, por una ventana", lo que recuerda a Amadis de Gaula que conoció a Oriana, en una entrevista nocturna alumbrada en la ventana por dos candelas ${ }^{53}$.

No solo algunos personajes medievales sirvieron de inspiración, también hay temas medievales en la base de algunas de las historias femeninas del Quijote. Un buen ejemplo es el tema de la sarracena en conflicto con su padre, de la que es buen ejemplo Zoraida, "tema "carolingio" de lo más típico" ${ }^{54}$ y que aparece en la Historia del emperador Carlomagno y de los doze pares de Francia. La historia de Zoraida, salvadora de un cautivo, tiene antecedentes en el Poema de Fernán González (s. XIII), donde el héroe castellano es salvado por su esposa doña Sancha. El tema de la liberación venía de la literatura clásica, y su ingreso en la literatura medieval se realiza con las cruzadas, en leyendas que eran claros ecos de cuentos arábigos ${ }^{55}$. Tiene también antecedentes en la leyenda de la Virgen de Liesse, con sólido arraigo en la época medieval ${ }^{56}$. Las relaciones del tema de Zoraida con sus precedentes franceses, lo deja apuntado el propio Cervantes ${ }^{57}$.

Aunque puede resultar inapropiado hablar de intertextualidad en el Quijote, es obvio que Cervantes se inspiró en escritores que le precedieron, y recibió una buena herencia del mundo medieval, europeo e hispano. En efecto, junto a la tradición literaria europea, hay en el Quijote influencia de la tradición literaria castellana, en concreto del Poema de Mío Cid. La cita a Teresa Panza con una saya tan corta que parecía «que se la habían cortado por vergonzoso lugar» (II, 50), tiene un claro precedente en los versos del romance de las "Quejas de Jimena»:

53 F. Marquez Villanueva, Personajes y temas del Quijote, p. 60.

54 F. Marquez Villanueva, Personajes y temas del Quijote, p. 138.

55 F. Marouez Villanueva, Personajes y temas del Quijote, p. 103, nota 29, apunta un cuento de Las mil y una noches como antecedente de esa historia.

56 Se encuentan parentescos de la leyenda mariana con los poemas de gesta franceses, las mil y una noches, y su reflejo en España en la leyenda de los siete infantes de Lara, el Poema de Fernán González y la leyenda de Maynete y Galiana.

57 ¿Qué ingenio puede haber en el mundo que pueda persuadir a otro que no fue verdad lo de la infanta Floripes y Guy de Borgoña? ¿Y lo de Fierabrás con la puente de Mantible, que sucedió en el tiempo de Carlomagno, que voto a tal que es tanta verdad como es ahora de dia? Y si es mentira, también lo debe de ser que no hubo Héctor, ni Aquiles, ni la guerra de Troya, ni los Doce Pares de Francia, ni el rey Artús de Ingalaterra, que anda hasta ahora convertido en cuervo, y le esperan en su reino por momentos. Y también se atreverán a decir que es mentirosa la historia de Guarino Mezquino, y la de la demanda del Santo Grial, y que son apócrifos los amores de don Tristán y la reina Iseo, como los de Ginebra y Lanzarote, habiendo personas que casi se acuerdan de haber visto a la dueña Quintañona, que fue la mejor escanciadora de vino que tuvo la Gran Bretaña" $(1,49)$ 


\author{
Enviéselo a decir, \\ envióme a amenazare \\ que me cortara mis haldas \\ por vergonzoso lugare
}

Esa correspondencia textual puede relacionarse con algo que puede ser una mera coincidencia: el papel de las mujeres en el Poema de Mio Cid y en el Quijote ${ }^{58}$. En ambas obras las mujeres tienen un papel fundamental. El primero no podria existir sin Jimena y sus hijas, el segundo tendria un sentido muy diferente sin la galeria de mujeres que desfilan por él. Dulcinea es esencial en el Quijote, como Doña Jimena lo es en el Poema del Cid. En ambas obras las mujeres sirven para que se luzca el héroe, el caballero; en ambas el matrimonio ocupa un lugar esencial. En el Poema del Cid fracasa el matrimonio impuesto por los padres, o por el rey en la figura de padre; en el Quijote triunfa el matrimonio no impuesto por la familia, el matrimonio por mutuo consentimiento, a contracorriente de su tiempo, ya que el Concilio de Trento había decretado lo contrario.

Exponer contradicciones constituye parte de la personalidad de Cervantes al contar historias. Buena muestra de ese estilo es el episodio de Dorotea en el que reúne "opuestas tradiciones literarias, de Edad Media y de Renacimiento" ${ }^{5}$. Cervantes no se inclina por una tradición u otra, pero como «portador de temas de su época" ${ }^{60}$, retrata mujeres del siglo XVII, con valores reconocibles en las mujeres medievales. Esto permitiría apuntar que los modelos femeninos en realidad no parecen cambiar, parecen inamovibles, dogmáticos casi, como era dogmática la Iglesia que los habia creado. Parece que los cambios sociales se desarrollaban de manera más lenta o ralentizada en lo referente a valores femeninos. Cambian algunas cosas, como la forma de conseguir el honor por las obras y no por el linaje, pero lo esencial permanece, y permanecerá asi durante siglos. Podría decirse que cambia la forma pero no el fondo.

El coniunto de mujeres del Quijote podrían presentarse como un magnífico retablo medieval, en el que cada cuadro hay una historia, y en cada historia hay una protagonista con don Quijote de fondo; las mujeres aparecen pintadas de acuerdo con las normas técnicas de la época, pero con un fondo ideológico inamovible, estático, rígido, que permite confirmar la idea de que cambian las formas pero no el fondo. Desmontar el cuadro para conocer mejor a esas mujeres puede hacerse de muchas maneras, una de ellas es la que se ha expuesto aqui, la otra sería mérito del propio Cervantes, que inició la deconstrucción, poniendo en tela de juicio algunas creencias, costumbres e ideas de su época, y mostrando él mismo las contradicciones y ambigüedades de los modelos femeninos que construía.

58 Sobre el papel de las mujeres en algunas obras literarias se expresa M. K. de Trinker, Las mujeres en el Don Quijote de Cervantes comparadas..., pp. 27-28, diciendo que sin Dulcinea es inımaginable el Quijote, en contra de la opinión de Ramiro de Maeztu quien en su obra Don Quijote Don Juan y la Celestina señalaba que no son esenciales los episodios amorosos de esas obras.

59 F. Márouez Villanueva, Personajes y temas del Quijote, p. 24.

60 Palabras de Américo Castro citadas por S. E. TRACHMAN, Cenvantes' Women of Literary Tradition, p. 37 